
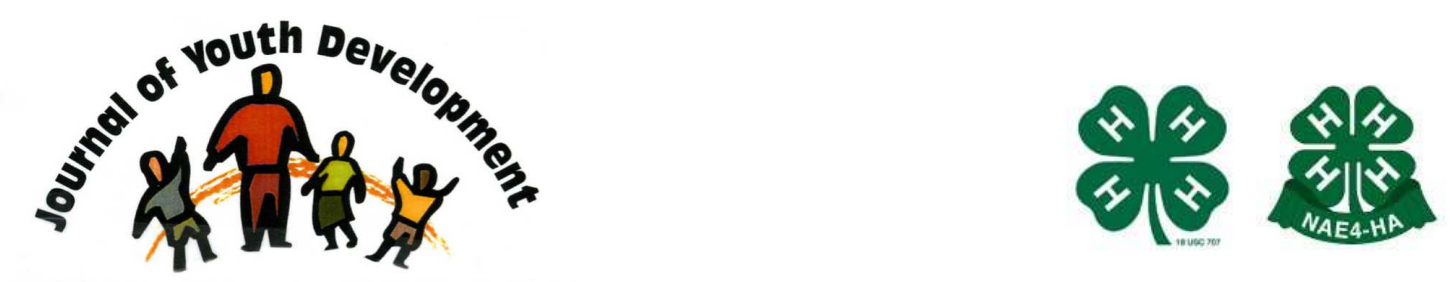

Bridging Research \& Practice

\title{
Promoting Civic Engagement, Critical Thinking and the Science of Photography through Photovoice
}

\author{
Julie Tritz \\ Wayne County Extension \\ West Virginia University \\ Wayne, WV \\ julie.tritz@mail.wvu.edu
}




\title{
JOURNAL OF YOUTH DEVELOPMENT \\ bridging research and practice

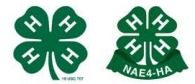

\section{Promoting Civic Engagement, Critical Thinking and the Science of Photography through Photovoice}

Julie Tritz

\begin{abstract}
Photovoice is part of a growing interest in using creative tools with youth groups as a means to increase involvement in the positive development of local communities. The goal of Photovoice is to allow youth to record, reflect and act on issues of importance to them through the production of still photographs. The methodology holds promise for youth development professionals in several ways. It teaches soft skills such as teamwork and critical thinking; fosters civic engagement and engages youth in learning about the science of photography. The article concludes with considerations and ideas for emulating the methodology in a local community.
\end{abstract}

\section{Introduction}

Photovoice is part of a growing interest in using creative, dynamic tools with community groups as a means to increase involvement and two-way communication in local development. The methodology was developed in the early 1990s by Caroline Wang with the University of Michigan and Mary Ann Burris with the University of London. Their work stemmed from a desire to help rural women in China influence local policies and programs (Wang, et al., 1996).

Youth development professionals often struggle to get youth involved in civic engagement exercises that are educational, engaging and fun. Studies show that Photovoice has helped in this regard by using photography as a means to engage youth in identifying what is working and what needs changing in local communities (Berman, et al., 2001; Strack, et al., 2004; Tritz, 2011; Wilson, et al., 2007).

The Photovoice methodology provides youth groups the time and space to record, reflect and act on various aspects of importance to them through the production of still photographs. These photographs are then shared with community leaders and policy-makers in the form of an exhibition as a means to increase awareness and incite positive social change. Wang, et al. (2004) describes how youth from Flint, Michigan shared their concerns of high unemployment, 
violence and image issues with community leaders that was instrumental in the construction of a Youth Violence Prevention Center in their community.

The Photovoice methodology is facilitated by an Extension educator, teacher or other youth development professional. Given that critical thinking and dialogue are central aspect of the methodology, it is deemed more effective with middle-school aged youth and older. An average Photovoice project will involve between 15-20 participants.

\section{The Photovoice Process}

The Photovoice methodology is a multi-step process that is participatory in nature where participants are behind the camera, creating the photographs and ultimately deciding which photographs will be featured in the exhibition. Facilitators guide and give leadership to the overall process which includes the following three steps.

1. Document and record a community's assets and concerns through the production of photographs,

2. Discuss and engage in critical thinking around the photographs produced,

3. Exhibit the photographs for community leaders, policy makers, family and friends.

The first step involves participants recording what is important about their community and what needs changing through the use of photography. To succeed with this first step, a community mapping exercise is effective in starting a conversation about community assets and concerns. Participants 'map' their community as they see it by documenting different landmarks, schools, housing divisions, parks, and rivers to name several. Before participants are given cameras, technical training in photography is provided as well as a discussion on ethical considerations when photographing in public.

Hergenrather, et al. (2009) review of 26 Photovoice studies found that $85 \%$ used disposable cameras whereas only two used digital cameras. While disposable cameras may seem dated, they provide a built in limit as to the number of photographs taken per participant. They are also easier and less expensive to replace in the event of an accident.

The second step involves a group discussion of the photographs. The mnemonic SHOWED is used to facilitate critical thinking of the photographs as presented by the participants (Wang et al, 1996).

- What do you See here?

- What is really Happening here?

- How does this relate to Our lives?

- Why does this concern, situation, strength exist?

- How can we become Empowered through our new understanding?

- What can we Do?

Through these discussions, participants identify the photographs that best capture their community's assets and concerns. The group works together as a team to identify and create an exhibition that will tell their story most effectively to community leaders and policy makers. It is best to scan photographs and project each on a screen to encourage full participation. The number of photographs is determined by the amount of space at the exhibition location. 
The final step in the Photovoice methodology is the exhibition. The purpose of the exhibition is to increase awareness and incite positive social change on the community assets and concerns. Community leaders and policy-makers are identified by participants and invited to attend and give reaction to the exhibition. Family and friends are also invited and in many cases provide the majority of the audience (Strack, et al., 2004). One or two members of the group are encouraged to facilitate the launch of the exhibition to give opportunity for public speaking and leadership skill development.

\section{The Potential Impact of Photovoice}

Photovoice is a promising program for several reasons. First, the methodology supports the development of soft skills such as oral communication, teamwork and collaboration skills, critical thinking and problem solving. As photographs are presented, discussed and debated using the mnemonic SHOWED, participants not only communicate their views but use critical thinking to analyze the various photographs. Participants work collaboratively to select the photographs to be featured in an exhibition.

Secondly, the methodology explores the science of photography which aligns with 4-H's science mission mandate. Youth are given technical training in key aspects of photography such as composition, lighting and framing prior to taking photographs. Photovoice allows youth to discover what constitutes a 'good' photograph through the process taking photographs and then analyzing them through the group discussion.

Another promising feature of Photovoice is its political dimension. Through Photovoice youth have an opportunity to have a 'voice' in the development of their communities. The public often has a limited role in the construction and maintenance of public policy. In fact, Tisdall \& Davis (2004) argue that all too often a youth's perspective is not accurately reflected in public policy. This feature aligns with 4-H's citizenship mission mandate as it facilitates youth to be contributing citizens in the communities that they live and/ or interact.

In total, Photovoice embraces the concept that a 'picture is worth a 1,000 words.' Photographs have the potential to teach, empower and influence policy. Photovoice is a process that teaches soft skills such as teamwork and critical thinking; fosters civic engagement and engages youth in learning about the science of photography.

\section{Putting the Photovoice Methodology into Practice}

Emulating the Photovoice methodology requires ample time and proper planning. It is important to point out that no one Photovoice project is the same. In fact, many vary in length, number of participants involved and money required.

Herganrather, et al. (2009) review of Photovoice projects shows that they range from 4 weeks in length to 36 weeks. Tritz (2011) conducted a Photovoice day camp over five consecutive days for youth ages 14-18 years. In this instance, approximately 10 hours were set aside for technical training and taking photographs of the community; 10 hours for group discussion and 10 hours to prepare the exhibition. Below are some additional considerations for Photovoice projects. 
- Budget: Consider what funds are available and what funds need to be generated through grants or other forms of support. Budget items include:

- Workshop supplies and refreshments,

- Disposable cameras (or digital),

- Mounting and hanging photographs (professionally mounted or use heavy card stock),

- Refreshments for the exhibition,

- Printing (hand-outs, program at exhibition)

- Group size: $10-12$ participants is ideal; $15-20$ is typical. In either case, one to two adult volunteers are needed for safety reasons and in managing project logistics.

- Identifying a Group: Since time is needed to implement the project, consider readymade audiences such as 4-H Club that meets regularly. Or conduct it as a school arts project. Another idea is to develop a day camp over spring or winter break or during the summer.

- Funding: Seek donations for disposal cameras from local business or photography shop. Consider charging participants a small fee; this builds ownership and helps cover costs. Identify in-kind contributions from the County Extension office, local school or other agencies (example: printing) that may help off-set project costs.

- Exhibition Location: Identify early on in the project. Libraries, banks or community centers are often free or inexpensive options. This will determine the amount of space for guests at the exhibition as well as the number of photographs that can be included in it. Also consider how photographs will be hung at the location.

- More information on Photovoice: This may be found by accessing the research articles below or by contacting the author.

\section{References}

Berman, H., Ford-Gilboe, M., Moutrey,Y.B., \& Cekic, S. (2001). Portraits of pain and promise: a photographic study of Bosnian youth. Canadian Journal of Nursing Research, 32 (4): 21-41.

Hergenrather, K.C., Rhodes, S.D. \& Bardhoshi, G. (2009). Photovoice as community-based participatory research: A qualitative review. American Journal of Health Behavior, 33 (6): 686698.

Strack, R.W., Magill, C., \& McDonagh, K. (2004), Engaging youth through Photovoice. Health Promotion Practice, 5 (1): 49-58.

Tritz, J. (2011). Exploring rural identity through Photovoice and participatory video. Unpublished doctoral dissertation. University College Dublin; Dublin, Ireland. 
Wang, C., Burris, M., \& Yueping, X. (1996). Chinese village women as visual anthropologists: A participatory approach to reaching policymakers. Social Science Medicine, 42 (10), 1391-1400.

Wang, C., Morrel-Samuels, S., Hutchison, P., Bell, L., \& Pestronk, R. (2004). Flint Photovoice: Community Building Amount Youths, Adults and Policy-makers. American Journal of Public Health, 94 (6), 911-914.

Wilson, N., Dasho, S., \& Martin, A. (2007). Engaging young adolescents in social action through photovoice. Journal of Early Adolescence, 27 (2): 241-261.

(C) Copyright of Journal of Youth Development Bridging Research and Practice. Content may not be copied or emailed to multiple sites or posted to a listserv without copyright holder's express written permission. However, users may print, download or email articles for individual use. 